\title{
BMJ Open Barriers to care for women with low- grade endometrial cancer and morbid obesity: a qualitative study
}

\author{
Maria C Cusimano, ${ }^{\oplus 1}$ Andrea N Simpson, ${ }^{1,2}$ Angela Han, ${ }^{1}$ Robin Hayeems, ${ }^{3,4}$ \\ Marcus Q Bernardini, ${ }^{1,5}$ Deborah Robertson, ${ }^{1,2}$ Sari L Kives, ${ }^{1,2}$ \\ Abheha Satkunaratnam, ${ }^{1}$ Nancy N Baxter, ${ }^{4,6}$ Sarah E Ferguson ${ }^{1,5}$
}

To cite: Cusimano MC, Simpson AN, Han A, et al. Barriers to care for women with low-grade endometrial cancer and morbid obesity: a qualitative study. BMJ Open 2019:9:e026872. doi:10.1136/ bmjopen-2018-026872

- Prepublication history and additional material for this paper are available online. To view these files, please visit the journal online (http://dx.doi. org/10.1136/bmjopen-2018026872).

Received 24 September 2018 Revised 27 May 2019

Accepted 7 June 2019

Check for updates

(c) Author(s) (or their employer(s)) 2019. Re-use permitted under CC BY-NC. No commercial re-use. See rights and permissions. Published by BMJ.

For numbered affiliations see end of article.

Correspondence to

Dr Sarah E Ferguson;

Sarah.Ferguson@uhn.ca

\section{ABSTRACT}

Objective Obesity is a major risk factor for low-grade endometrial cancer. The surgical management of patients with obesity is challenging, and they may face unique barriers to accessing care. We completed a qualitative study to understand the experiences of low-grade endometrial cancer patients with morbid obesity, from symptom onset to diagnosis to surgery.

Design Semi-structured interviews were performed with endometrial cancer patients with morbid obesity (body mass index $(\mathrm{BMI}) \geq 40 \mathrm{~kg} / \mathrm{m}^{2}$ ) referred for primary surgery. Transcribed interviews were coded line-by-line and analysed using an interpretive descriptive approach that drew on labelling theory to understand patients' experiences. Thematic sufficiency was confirmed after 15 interviews.

Setting Two tertiary care centres in Toronto, Ontario, Canada.

Participants Fifteen endometrial cancer patients with a median age of 61 years (range: 50-74) and a median BMI of $50 \mathrm{~kg} / \mathrm{m}^{2}$ (range: $44-70$ ) were interviewed.

Results Thematic analysis identified that (1) both patients and providers lack knowledge on endometrial cancer and its presenting symptoms and risk factors; (2) patients with morbid obesity are subject to stigma and poor communication in the healthcare system and $(3,4)$ although clinical, administrative, financial, geographic and facility-related barriers exist, quality care for patients with morbid obesity is an achievable goal.

Conclusions Improved education on the prevention and identification of endometrial cancer is needed for both patients and providers. Delivery of cancer care to patients with morbid obesity may be improved through provider awareness of the impact of weight stigma and establishing streamlined care pathways at centres equipped to manage surgical complexity.

\section{INTRODUCTION}

Low-grade endometrial cancer is more strongly associated with obesity than any other malignancy. ${ }^{1}$ Obesity confers not only a 3-fold to 10-fold increase in the incidence of endometrial cancer, but also a 2-fold to 6 -fold increase in the risk of endometrial cancer death. ${ }^{1-3}$ The standard of care for

\section{Strengths and limitations of this study}

The qualitative design of this study made it possible to obtain detailed personal accounts of patients' referral experiences, which are not captured by quantitative data.

- The use of an interpretive descriptive approach enabled generation of knowledge that is relevant to healthcare providers in multiple roles across multiple disciplines, including primary care, obstetrics and gynaecology and oncology.

- Our sample only includes women who were treated in urban academic centres and who have a level of comfort in discussing their challenges with obesity.

patients diagnosed with endometrial cancer is total hysterectomy, bilateral salpingo-oophorectomy and lymph node assessment by a laparoscopic or robotic approach to decrease surgical morbidity. ${ }^{4}$ However, these minimally invasive approaches become challenging as body mass index (BMI) increases, and not all surgeons or centres are equipped to manage the technical and anaesthetic difficulties associated with obesity. ${ }^{5-7}$

Such issues accessing surgical care may be exacerbated by weight bias in healthcare. There is a growing body of literature suggesting that patients with obesity face discrimination. ${ }^{8-10}$ Providers tend to perceive patients with obesity as undisciplined or unintelligent, or may use obesity as a reason to withhold medical care without evidence to do so. ${ }^{111}$ Providers also offer less counselling and appear more ambivalent about health interventions when treating patients with obesity. $^{13} 14$ These issues have been shown to contribute to negative patient-provider interactions and patient avoidance of healthcare. $^{912-14}$

Although $>50 \%$ of women undergoing surgery for endometrial cancer have concurrent obesity (BMI $30-40 \mathrm{~kg} / \mathrm{m}^{2}$ ) or morbid 
obesity (BMI $\geq 40 \mathrm{~kg} / \mathrm{m}^{2}$ ), there is no literature exploring barriers to care or possible weight stigma in this population. ${ }^{1516}$ This study aims to answer the following question: What are the experiences of women with low-grade endometrial cancer and morbid obesity as they navigate the healthcare system from symptom onset to diagnosis to surgery? Understanding the experiences of this population has important implications for improving the quality of their care.

\section{MATERIALS AND METHODS \\ Study design and setting}

We performed a qualitative study to obtain detailed personal accounts of women's referral experiences, which are not captured by quantitative data. Participants were recruited from Princess Margaret Hospital and St. Michael's Hospital, tertiary centres in Toronto, Canada. Unlike the majority of hospitals in the province, both centres have da Vinci surgical robots (Intuitive Surgery, Sunnyvale, California, USA), which have been shown to facilitate minimally invasive hysterectomy in patients with morbid obesity. ${ }^{7}$ As a result, these centres receive numerous surgical referrals for this population from family doctors, gynaecologists and oncologists spanning academic, community, rural and urban practices. This ensured recruitment of patients from diverse backgrounds.

\section{Sampling and recruitment}

Consecutive patients who met the following inclusion criteria were approached by a research assistant in person at the time of a clinic appointment: (1) diagnosis of low-grade endometrioid adenocarcinoma of the endometrium; (2) $\mathrm{BMI} \geq 40 \mathrm{~kg} / \mathrm{m}^{2}$; (3) plan to be treated by primary hysterectomy or receipt of primary hysterectomy in preceding 6 months; (4) ability to communicate in English and (5) ability to provide informed consent. Patients who were not surgical candidates due to severe medical comorbidities were excluded, as we aimed to capture barriers to surgery in patients with morbid obesity who had no contraindications.

\section{Data collection}

Literature on weight stigma and labelling theory were used to create a semi-structured interview guide (online supplementary appendix 1). Labelling theory originated in the sociology of deviance, and includes (1) primary labelling, which reflects how society reacts to a group of individuals who diverge from standard cultural norms; and (2) secondary labelling, which reflects how those individuals alter their own self-regard and social roles in response to societal stigmatisation. ${ }^{17}{ }^{18}$ Questions were based on this theoretical framework and were thus designed to understand participants' experiences in and responses to the healthcare system. The interview guide was pilot-tested on two individuals without endometrial cancer to ensure clarity, and then modified iteratively based on emerging interview findings.

Three researchers (MCC, ANS and AH) carried out one-on-one telephone interviews using the interview guide. We chose telephone interviews due to the sensitive nature of the subject matter and concerns that the body habitus of the interviewers may influence patients' responses. All interviews were audiorecorded. After each interview, initial impressions and the tone of the conversation were documented to provide context for the analysis. $^{19}$

With respect to researcher characteristics, MCC and ANS were graduate students and clinical trainees in Obstetrics and Gynaecology, and $\mathrm{AH}$ was a senior medical student. Instruction and oversight were provided by $\mathrm{RH}$, an expert in qualitative methodology. While MCC, ANS and AH had previously interacted with endometrial cancer patients, they had no involvement in the care of any study participants. All researchers bracketed their assumptions based on previous experiences with this patient population, and the contextual perspective of the researchers was discussed during data collection and analysis.

\section{Data analysis}

Interpretive description, a qualitative research approach grounded in applied disciplines, was used to construct an account of participants' experiences. ${ }^{20}$ Interviews were de-identified, transcribed verbatim and audited for accuracy. Throughout the auditing process, a rudimentary analysis was performed where initial ideas were documented in the transcript margins and key phrases were highlighted. ${ }^{19}$ Using NVivo (V.11), two researchers (MCC and ANS) then coded transcripts line-by-line for significant quotations, which were developed into themes (clusters of meaning) inductively and deductively drawing on labelling theory. The first three transcripts were coded by MCC and ANS concurrently so that a common codebook could be constructed, and remaining transcripts were coded independently. Researchers updated the codebook as themes emerged, and early transcripts were secondarily analysed for these new themes. Interviews were conducted until thematic sufficiency was achieved. Themes were ultimately grouped to construct a rich description of the meaning of participants' experiences. ${ }^{20-22}$ To illustrate key themes, MCC and ANS reviewed each transcript for representative quotations and included those that were independently selected by both researchers.

\section{Patient and public involvement}

The research question and qualitative approach were selected in order to directly elicit patient perceptions of their experience, and to thus understand their concerns, preferences and priorities. However, patients or the public were otherwise not formally involved in the design, recruitment or conduct of the study. 


\begin{tabular}{ll} 
Table 1 & \multicolumn{1}{c}{ Characteristics of the study participants $(\mathrm{n}=15)$} \\
\hline Characteristic & Value \\
\hline Age, median (range) years & $61(50-74)$ \\
Body mass index, median (range) $\mathrm{kg} / \mathrm{m}^{2}$ & $50(44-70)$ \\
Specialists seen, median (range) & $2(2-4)$ \\
Geographic distance from treating hospital, & $\mathrm{n}(\%)$ \\
$<50 \mathrm{~km}$ & $9(60 \%)$ \\
$>50 \mathrm{~km}$ & $6(40 \%)$ \\
Initial symptoms, $\mathrm{n}(\%)$ & $12(80 \%)$ \\
Vaginal bleeding & $3(20 \%)$ \\
Incidental finding during routine care
\end{tabular}

\section{RESULTS}

Twenty-two patients were approached and 15 provided consent and were interviewed (table 1). Few new themes emerged after 11 interviews, and thematic sufficiency was confirmed after 15 interviews. The median age of participants was 61 years (range: 50-74), and the median BMI was $50 \mathrm{~kg} / \mathrm{m}^{2}$ (range: 44-70). Geographic distance from the treating centre ranged from 10 to $1500 \mathrm{~km}$. Every patient saw two to four specialists (gynaecologists, gynaecologic oncologists, medical/radiation oncologists) before being consented for surgery. Participants' experiences reflected a lack of knowledge on endometrial cancer, instances of stigmatisation or negative communication in the healthcare system and barriers to quality cancer care (table 2).

\section{Patients and providers lack knowledge on endometrial cancer}

Prior to their diagnosis, many participants simply had no idea there was 'such a thing as endometrial cancer' (ID 3). One patient explained, "It's just not a popular cancer. People don't understand it. If you say breast cancer, people know it. If you have prostate cancer, they know what it is. I had never even heard of (endometrial cancer) (ID 11)."

Participants also lacked knowledge on the significance of postmenopausal or abnormal uterine bleeding before their diagnosis. Except for one individual who had been concerned about cervical cancer, patients had not known that these symptoms could indicate malignancy. While most notified their family physician regardless, several did not or waited years before doing so. In these cases, participants either did not think their bleeding symptoms 'were a big deal' (ID 4), believed they were simply a 'change-in-life-thing' (ID 12) or had skewed perceptions of what constituted normal cycles. One participant stated, "I've had menstrual problems, absent periods, infertility, ovarian cysts, for my entire life. So having pain, having odd menstruation, having periods absent for months on end, none of that was new to me (ID 3)."

Participants also described situations in which their primary care providers failed to recognise postmenopausal and abnormal uterine bleeding as symptoms concerning for cancer. While many physicians did refer to a gynaecologist, some attributed the symptoms to structural causes or perimenopause without investigating further, and others ordered lab tests or imaging rather than an endometrial biopsy. Many participants experienced worsening of symptoms before a diagnosis was made. One participant stated, "I couldn't get the bleeding to stop on its own, and I was afraid of passing out and bleeding more. So I started calling 911 (ID 15).” For others, the experiences of family or friends led them to carry out their own research and persist in having their symptoms evaluated: "I went back to my doctor after my friend passed (away from cancer) and said, 'This bleeding is going on unabated and it is bizarre. No woman I know puts up with this.' (My doctor) again brought up about the fibroids. She said-'I can send you for another ultrasound.' And, I said-'Yes, please do, but I also want a biopsy' (ID 3)."

Similarly, no participant had known that obesity is a risk factor for endometrial and other types of cancers prior to their diagnosis. One participant summarised, "Obesity is a terrible thing because it affects so many things... but I did not know that it would affect cancer (ID 13)." Most agreed that messaging around endometrial cancer as an entity and obesity as a risk factor was inadequate: "It's definitely an educational thing. My sisters are overweight and past menopause. They should be getting checked too (ID 8)."

\section{Endometrial cancer patients with obesity are subject to stigma and poor provider communication}

Participants highlighted concerns with how their healthcare providers had communicated with them about obesity. First, most providers had simply not discussed it: almost all participants learnt about the link between obesity and endometrial cancer through their own online searches and independent reading. Second, if physicians did address obesity, it was usually at the time of diagnosis, and patients questioned this approach. While some appreciated the 'wake-up call' (ID 14), others felt that discussing obesity at diagnosis was futile or placed blame on the patient: "I don't know whether it was really necessary to tell me because I was so obese that that's why I got cancer. It's sort of after the fact. It was done in a very sensitive way, but I don't know what the point was (ID 2)."

Most recently diagnosed participants expressed a desire to have been counselled specifically on the association between obesity and endometrial cancer earlier in life. One participant stated, "If there really is such a huge risk for women that are overweight, then it really should be more pronounced. Doctors should be bringing that to women's attention all the time. Just like now you smoke, you get lung cancer, period. If you're overweight, or this much obese, you're going to get cancer. That should be told (ID 5)."

In line with primary labelling theory, some patients felt they were treated differently than normal weight individuals. For example, some were offered non-curative alternatives to surgery because of their body weight: "She didn't like to deal with me because of my body weight. She wasn't willing to do anything, other than radiation. 


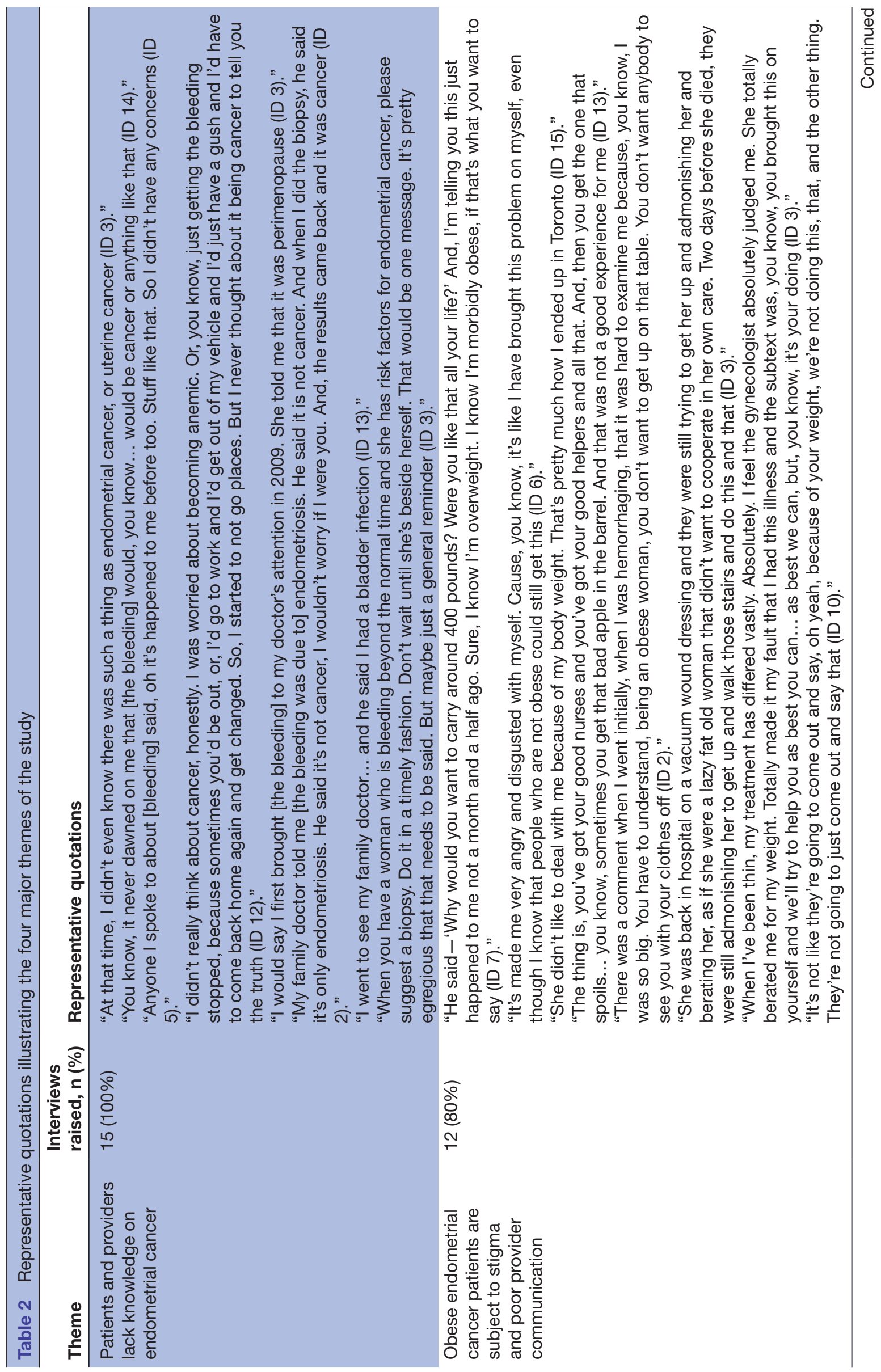




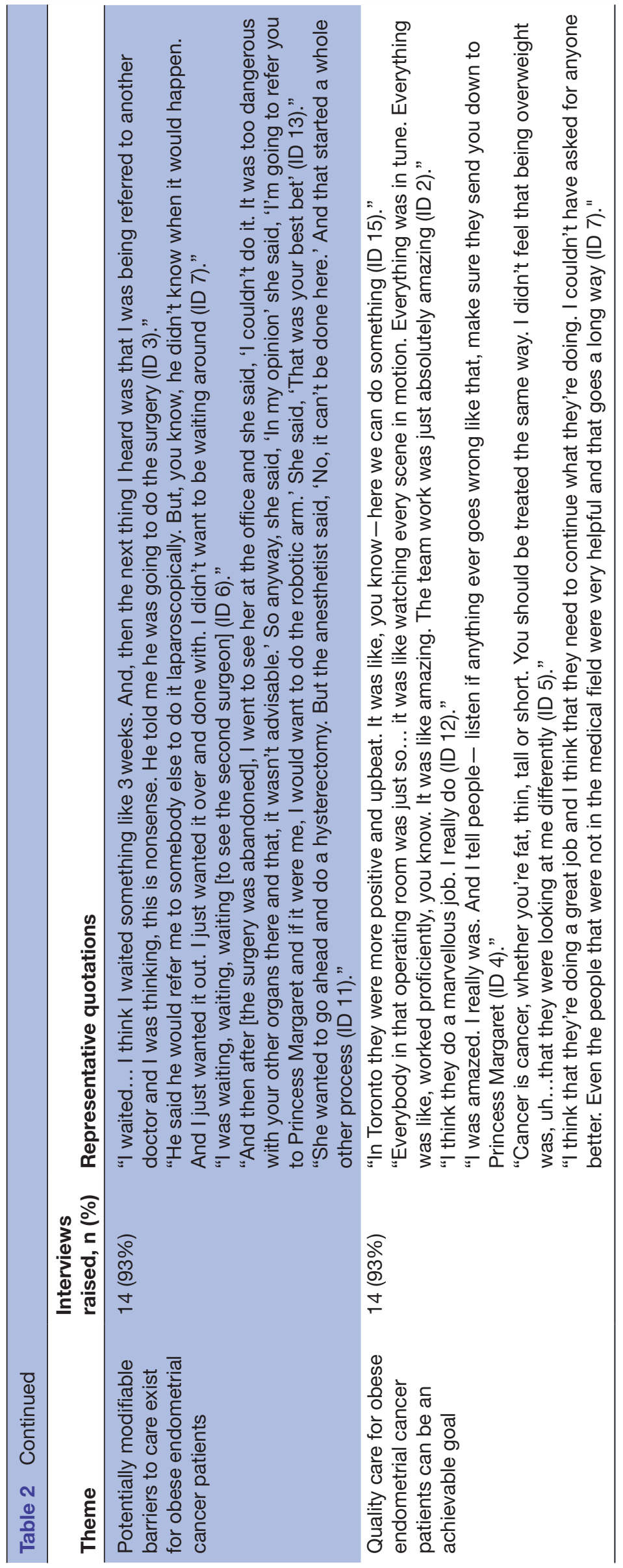


That was the attitude I got. Basically it's-Oh you've got cancer. Have a good life, what's left of it-you know (ID 15)."

In line with secondary labelling theory, several participants discussed prior stigmatising experiences that led to avoidance of healthcare. One participant stated, "I had a doctor say to me when I went for a Pap smear once'This is impossible, there's so much fat down here.' Well, I didn't want to go for a Pap test ever again (ID 2)." Another participant who had previously been referred for knee surgery described how her doctor had implied that obesity was merely a choice: "I had the surgeon say to me- 'Why would anyone want to be fat like that?' (ID 7)." Some participants avoided the healthcare system altogether because their previous health complaints had always been attributed to their weight: "I figured if I have like, joint pain or you know, any little issue, it would be because of my weight. If I go see the doctor, he's going to say the obvious, you know what I mean? Lose weight (ID 14)."

However, not all participants felt that their weight adversely affected their interactions with the healthcare system. Three had never felt stigmatised, saying, "I don't believe I've been treated differently at all (ID 10)." Others acknowledged a potential issue but were unwilling to let others influence their own self-worth because of their weight: "It's not my body fat. I'm what is inside of me. I don't let that dictate how I feel, or how people treat me. Sometimes people can be crude and make remarks and what not and you ignore that sort of thing. That's your opinion, fine. I know who I am. I'm a good person. I've got a lot of self-confidence. I don't need your opinion. I know that I'm overweight, but that's for me to deal with, not you (ID 13)."

\section{Potentially modifiable barriers to care exist for endometrial cancer patients with obesity}

Barriers to care emerged as a common theme. Most barriers identified by participants were universal, in that they were likely experienced by both obese and non-obese patients. These included administrative, geographic and financial challenges (table 3). However, other barriers were likely obesity-specific. First, many participants described diagnostic delay due to struggles in obtaining an endometrial biopsy and/or imaging; specifically, physicians frequently needed to perform a pelvic examination and biopsy under general anaesthesia, or imaging tests were not possible or indeterminate due to body habitus. A participant whose diagnosis was made months after presentation stated, " They tried two D\&Cs eventually. The first one was inconclusive. The second one they had more material that I guess gave them some results. And then they did a CT scan. Well, they weren't sure, because... it was a size issue. They weren't sure their CT scan was big enough for me. Eventually they decided I'd fit their parameters. I guess I got small enough to fit in the CT scanner."
Second, a small number of participants experienced treatment delay due to late cancellation or even intraoperative abandonment of surgery. One patient noted, "I got to the point where I had a surgery date and everything. But the anesthetist classed me as being too high risk for that hospital and said no, it could not be done there. So that was cancelled and I was referred to the other hospital (ID 15)." Finally, all participants experienced treatment delay due to requiring multiple referrals before finding an accepting surgical team. One participant, who saw four gynaecologists before surgery, described how discouraging this process was for her: "By this time I felt like I was auditioning for a show. And that if I didn't audition well, my cancer... or my surgery would be delayed again (ID 3)."

Participants also discussed how the healthcare system is simply not equipped to accommodate individuals with morbid obesity. Deficiencies in the size or structure of waiting rooms, CT scanners, operating room tables and medical equipment were described. One patient summarised these issues when she said, "It can be embarrassing when the nurses say, oh, we don't have a blood pressure cuff your size, so we'll have to put it on your forearm. Or that their chairs are so darn narrow, with arms that you can't sit on them in the waiting room (ID 6)."

Importantly, participants discussed a lack of effective weight loss interventions. Available weight loss programmes were seen as inadequate for women with morbid obesity. One participant stated, "Weight loss strategies need to be meaningful ones. Maybe there's some people who need to lose 10 or 15 pounds for bikini season. But people who get to be my size, you wonder how can you ever get that big? If you can get that big, there's something going on metabolically. This is not a normal process and a normal diet is not going to fix that (ID 3)."

Others discussed their repeated struggles with affording and maintaining a healthy lifestyle: "Well, what can you do? I've tried my whole life (ID 4)." The few patients who did take initiative to lose weight before surgery were disappointed when their efforts were not acknowledged by their healthcare providers.

\section{Quality care for endometrial cancer patients with obesity is an achievable goal}

Despite these barriers, almost all participants felt that they had been well cared for overall, in that their endometrial cancer had been ultimately treated appropriately by an expert surgeon. Indeed, participants appreciated when community physicians recognised the limitations of their centres and referred them to a more appropriate surgical team. When asked how she felt after her gynaecologist disclosed he was unable to perform her procedure due to the medical and surgical risks of morbid obesity, one participant recalled, "Actually, at the time I was, you know, kind of iffy about it but I almost immediately thought, thank you so much because at least you are saying you can't do it and you are sending me to someone that can. 
Table 3 Representative quotations illustrating barriers to care for endometrial cancer patients

\begin{tabular}{|c|c|}
\hline Barrier & Representative quotations \\
\hline Administrative & $\begin{array}{l}\text { "My family doctor referred me to a gynecologist and he put on it ASAP. I hadn't heard back so I called the } \\
\text { gynecologist's secretary and she said, 'Oh, she said, I haven't even had time to look at the faxes yet.' And she } \\
\text { said, 'Well, if you're a new patient, you've got to wait } 2 \text { to } 3 \text { months before you see the doctor anyway. So, you } \\
\text { know, it just didn't go good at first (ID 2)." } \\
\text { "Every day that went by, it wasn't happening. I would call her office. I would ask if the referral had been made. } \\
\text { They would say yes. I would call the places that the referral was supposed to be made and they would tell } \\
\text { me they hadn't received my referral and then I would go back to her. So, for those weeks, I was in her office } \\
\text { almost every other day and I was on the phone to her office, every day (ID 3)." } \\
\text { "I already told you that the gynecologist did not send all of the information down to Princess Margaret, so that } \\
\text { was a delay (ID 5)." } \\
\text { "It's a bit confusing going through the system. You're dealing with so many people who all have a specialized } \\
\text { function and it would be nice to say, okay, so [the doctor] has a nurse, she has an assistant, these are the } \\
\text { people you call for booking appointments, you know. There's just so many people to deal with (ID 6)." }\end{array}$ \\
\hline Geogr & $\begin{array}{l}\text { "By the time we got home with the traffic and all that, it was like } 2 \text { o'clock in the morning, by the time we went } \\
\text { to bed. And we had got up at } 6 \text { o'clock to pack the truck, so. I mean, you know, it was pretty brutal. So, that's } \\
\text { why we decided that, yeah, we're staying in a motel, even if I can't afford it (ID 14)." } \\
\text { "There was a lot of stress and a lot of doctors meetings and appointments in Toronto, which isn't where I live } \\
\text { and I'm not familiar with (ID 12)." } \\
\text { "How was the process? Other than having to travel 4-1/2 hours, um, I... I had no issues. Like, I said, other } \\
\text { than trying to find a motel and, um, and, the traveling (ID 14)." } \\
\text { "If they're out of Toronto, my suggestion would be that they take them in the night before instead of the } \\
\text { morning of. Because it's difficult especially for somebody that, you know, has to get a ride there. Like, that's } \\
\text { the difficult part, right. That was the hardest thing about the whole thing, really. Was getting a ride here (ID 4)." }\end{array}$ \\
\hline Fina & $\begin{array}{l}\text { "I try not to eat what the dietitian say I'm not to eat, but, you know, sometimes you just don't have the funds } \\
\text { to buy what you need. So, sometimes whatever you're not to eat, that's the thing you're eating. And, then, you } \\
\text { know, you put on the weight and it's very hard to take off. So, that is my problem (ID 9)." } \\
\text { "It's just, I mean, you know, financially it's really hard for a person. They wanted me to come originally on the } \\
15^{\text {th }} \text {. Well, I don't live just across the street, you know. I mean, it costs big dollars. You can't get a seat sale, } \\
\text { because, you know, you're not far enough down the line. And then to stay in a hotel. You can't get there early } \\
\text { enough, because they want you there for 7:00 in the morning and there's no flights, so you have to go the } \\
\text { night before. It's like, with everything. And, you can't get a hotel room for less than } \$ 230 \text { a night (ID 7)." } \\
\text { "I'm just like everybody else, I live from pay cheque to pay cheque and I have no short-term disability, only } \\
\text { long-term. So, you have to go on unemployment. And, you have a waiting period (ID 12)." } \\
\text { "The parking is killing us, you know, at the hospital and that. Big bucks. Oh my God. Yeah (ID 13)." } \\
\text { "The Northern Ontario Travel Grant did help offset a little bit, especially with the traveling. But I mean for the } \\
\text { motel, well no matter where you go, they'll pay only a set amount. So that did help us a little to offset but it } \\
\text { was frustrating (ID 14)." }\end{array}$ \\
\hline
\end{tabular}

We're not beating around the bush. You're not going to try and then tell me, oh sorry, can't do it, so that takes more time. So I had no problem with it (ID 4)."

Many participants were 'in awe' (ID 13) of how quickly and smoothly their care progressed once they arrived at a centre that was comfortable offering minimally invasive surgery to patients with morbid obesity. One participant stated, "Once you got there, everything was all put in perspective. All in order. That part of the system is working (ID 7)." Another participant who was seen at five centres prior to surgery understood that the referrals were in her best interest but would have appreciated a more direct route.

\section{DISCUSSION}

This qualitative study explored the referral experiences of women with endometrial cancer and morbid obesity. Our results identify concerning knowledge gaps in these women, and reveal opportunities in which both prevention and survivorship strategies, accessibility to care and provider communication could be improved.

None of the participants in this study knew that irregular or ongoing postmenopausal bleeding were symptoms of endometrial cancer prior to their diagnosis. Participants were also not aware of endometrial cancer as an entity, or that obesity placed them at especially high risk of the disease. Survey-based studies similarly show that only $30 \%$ of general population women know that vaginal bleeding may be a sign of malignancy ${ }^{23} 24$ and $25 \%$ list cancer as a health condition that could result from being overweight or obese. ${ }^{25}$ These results suggest a pressing need for public education on endometrial cancer and its presenting symptoms, as well as targeted counselling and screening by physicians. Media campaigns have previously been used to educate on the association between rectal bleeding and colorectal cancer, ${ }^{26}$ and haematuria 
and bladder cancer. ${ }^{27}$ Similar initiatives on the significance of abnormal vaginal bleeding, led by societies such as the American College of Obstetrics \& Gynecology or the Royal College of Obstetrics \& Gynecology, could help in closing this knowledge gap. Providers should also be encouraged to specifically counsel their patients with obesity about the risks and warning signs of endometrial cancer. Educating this high-risk patient population may ultimately enable timely diagnosis and implementation of strategies for disease prevention.

Participants expressed a desire for knowledge and interventions earlier in life that might have prevented the development of endometrial cancer, but at the same time highlighted a lack of effective strategies and support for sustainable weight loss. Alternate approaches for endometrial cancer prevention may thus be valued and accepted by this patient population, even at a young age. Combined contraceptives and progestin-containing intrauterine devices are simple, cost-effective interventions that should be considered routinely for women with morbid obesity, particularly those with additional risk factors such as anovulation. ${ }^{28} 29$

Our data suggest that the postoperative period can be used as a window of opportunity to address the long-term health of endometrial cancer patients by initiating conversations about obesity and lifestyle modification. Although participants questioned whether physicians should mention obesity while breaking bad news, they universally appreciated frank discussions about the surgical and medical risks of obesity later during the course of treatment. Existing literature reinforces these findings: over $90 \%$ of women with endometrial hyperplasia/cancer and obesity report that it would be appropriate for their gynaecologic oncologist to discuss weight loss, ${ }^{30}$ and those who receive such a counselling are more likely to attempt weight loss postoperatively. ${ }^{31}$ Over $50 \%$ of endometrial cancer patients with obesity accepted a bariatric referral when approached by their oncologist within 1 month of surgery, compared with only $35 \%$ after 1 year and $<10 \%$ by 3 years. ${ }^{30}$ When one considers that endometrial cancer patients with morbid obesity are more likely to die of their cancer and also of comorbidities compared with leaner counterparts, it is clear that addressing obesity after curative treatment is critical to optimising long-term health for this population. ${ }^{3} 32$

Such a counselling on obesity must be delivered in a way that limits the stigmatisation and healthcare avoidance described by our participants. Patients should be asked what terms are acceptable when discussing their weight. ${ }^{33} 34$ We adhered to the WHO classification for obesity, but recognise that BMI alone is not the defining feature of obesity and patients may prefer other terminology. Providers should also avoid advising 'diet and exercise' without further support; this strategy is oversimplified and inadequate in this population, and may perpetuate weight stigma by implying that patients with morbid obesity are lazy or lack self-control. ${ }^{10}$ Providers should instead highlight the importance of a healthy lifestyle at any body size, encourage normalised eating rather than dieting and offer formal referrals for bariatric surgery or professional supervision of weight loss. ${ }^{30} 35$

Our participants indicated that high-quality care for women with endometrial cancer and morbid obesity is an achievable goal, but also identified barriers that must be addressed. Several women included in this study described treatment delay due to cancelled or abandoned surgeries at centres with inadequate resources to manage their complexity, and this is certainly a quality of care issue that should be avoided. Women with morbid obesity would likely benefit from being managed in tertiary care centres with robotic technology, ${ }^{7}$ and many participants in this study described feeling well cared for at such centres. However, redirecting referrals to these centres must be balanced against cost and travel requirements, which were also raised by patients as significant challenges. Therefore, if care for patients with morbid obesity is streamlined in this way, other barriers to accessibility must be simultaneously addressed. ${ }^{36}$

While informative about the referral experiences of endometrial cancer patients with morbid obesity, our study has several limitations. First, we only interviewed women treated in urban academic centres, and their experiences may not be representative of women undergoing surgery in other practice settings. However, many participants were first assessed in community centres, and we captured those experiences as well. Second, obesity is a sensitive topic, and not all patients may be willing to participate in an interview where this is the central focus. Thus, our study only includes women who have a level of comfort in discussing obesity.

Our study also has many strengths. By using a qualitative approach, we gained insight into the unique challenges experienced by this patient population and the ways in which they feel obesity should be addressed by healthcare providers. Our findings will be instrumental in guiding communication and care delivery to endometrial cancer patients with obesity. Our results may apply to other populations as well: the barriers described by participants may be relevant to all women with endometrial cancer and to patients with other obesity-related diseases.

Future research is required to clarify the impact of obesity on endometrial cancer care. Epidemiological studies will be important in quantifying whether patients with obesity indeed face diagnostic or treatment delays, and whether patterns of oncological care differ for patients with and without concurrent obesity. From a qualitative perspective, evaluating perceived barriers to care for this population from the perspective of physicians will be critical in identifying opportunities for intervention and knowledge translation.

In summary, women with low-grade endometrial cancer and morbid obesity have important knowledge gaps, and may face barriers and stigmatisation in the healthcare system. Education around endometrial cancer, including its warning signs and association with obesity, is needed for both patients and providers. Coordinating care to 
centres with expertise in managing surgically complex cases may reduce delays and improve the overall treatment experience for women with morbid obesity. Finally, postoperative survivorship offers a unique window of opportunity to address obesity, and thus optimise longterm health for this population.

\section{Author affiliations}

${ }^{1}$ Obstetrics and Gynaecology, University of Toronto, Toronto, Ontario, Canada ${ }^{2}$ Obstetrics and Gynaecology, St. Michael's Hospital, Toronto, Ontario, Canada ${ }^{3}$ Child Health Evaluative Sciences, Hospital for Sick Children, Toronto, Ontario, Canada

${ }^{4}$ Institute of Health Policy, Management, and Evaluation, University of Toronto, Toronto, Ontario, Canada

${ }^{5}$ Gynaecology Oncology, Princess Margaret Cancer Centre, Toronto, Ontario, Canada ${ }^{6}$ General Surgery, St. Michael's Hospital, Toronto, Ontario, Canada

Acknowledgements We thank the physicians, nurses and research assistants who assisted with this study, and the patients who volunteered their time to participate.

Contributors Study conception and design: ANS, RH, DR, NNB and SEF; Acquisition of data: MCC, ANS, AH, MQB, DR, SLK, AS and SEF; Analysis and interpretation of data: MCC, ANS, AH and RH; Original drafting of manuscript: MCC and ANS; Critical revision of manuscript and final approval of manuscript: All authors

Funding This work was supported by the Department of Obstetrics and Gynecology Mount Sinai Hospital/University Health Network Research Fund, and the University of Toronto Chair's Summer Studentship Award.

Competing interests None declared.

Patient consent for publication Obtained.

Ethics approval Research ethics board approval was obtained at both Princess Margaret Hospital and St. Michael's Hospital (ID 17-5228).

Provenance and peer review Not commissioned; externally peer reviewed.

Data sharing statement The unpublished data have been de-identified and are not available to anyone other than the researchers, as per Research Ethics Board guidelines at our institutions.

Open access This is an open access article distributed in accordance with the Creative Commons Attribution Non Commercial (CC BY-NC 4.0) license, which permits others to distribute, remix, adapt, build upon this work non-commercially, and license their derivative works on different terms, provided the original work is properly cited, appropriate credit is given, any changes made indicated, and the use is non-commercial. See: http://creativecommons.org/licenses/by-nc/4.0/.

\section{REFERENCES}

1. Modesitt SC, van Nagell JR. The impact of obesity on the incidence and treatment of gynecologic cancers: a review. Obstet Gynecol Surv 2005;60:683-92.

2. Calle EE, Rodriguez C, Walker-Thurmond K, et al. Overweight, obesity, and mortality from cancer in a prospectively studied cohort of U.S. adults. N Engl J Med 2003;348:1625-38.

3. Arem H, Irwin ML. Obesity and endometrial cancer survival: a systematic review. Int J Obes 2013;37:634-9.

4. Koh WJ, Abu-Rustum NR, Bean S, et al. Uterine Neoplasms, Version 1.2018, NCCN Clinical Practice Guidelines in Oncology. J Natl Compr Canc Netw 2018;16:170-99.

5. Bernardini MQ, Gien LT, Tipping H, et al. Surgical outcome of robotic surgery in morbidly obese patient with endometrial cancer compared to laparotomy. Int J Gynecol Cancer 2012;22:76-81.

6. Walker JL, Piedmonte MR, Spirtos NM, et al. Laparoscopy compared with laparotomy for comprehensive surgical staging of uterine cancer: Gynecologic Oncology Group Study LAP2. J Clin Oncol 2009:27:5331-6.

7. Cusimano MC, Simpson AN, Dossa F, et al. Laparoscopic and robotic hysterectomy in endometrial cancer patients with obesity: A systematic review and meta-analysis of conversions and complications. Am J Obstet Gynecol 2019.

8. Puhl R, Brownell KD. Bias, discrimination, and obesity. Obes Res 2001;9:788-805.
9. Puhl RM, Brownell KD. Confronting and coping with weight stigma: an investigation of overweight and obese adults. Obesity 2006;14-1802-15.

10. Puhl RM, Heuer CA. Obesity stigma: important considerations for public health. Am J Public Health 2010;100:1019-28.

11. Phelan SM, Burgess DJ, Yeazel MW, et al. Impact of weight bias and stigma on quality of care and outcomes for patients with obesity. Obes Rev 2015;16:319-26.

12. Brownell KD, Puhl RM. Stigmatized patients' right to equal treatment Virtual Mentor 2006;8:298-302.

13. Amy NK, Aalborg A, Lyons $P$, et al. Barriers to routine gynecological cancer screening for White and African-American obese women. Int J Obes 2006;30:147-55.

14. Friedman AM, Hemler JR, Rossetti E, et al. Obese women's barriers to mammography and pap smear: the possible role of personality. Obesity 2012;20-1611-7.

15. Mahdi $H$, Jernigan AM, Aljebori $Q$, et al. The impact of obesity on the 30-day morbidity and mortality after surgery for endometrial cancer. J Minim Invasive Gynecol 2015;22:94-102.

16. Suidan RS, He W, Sun CC, et al. Impact of body mass index and operative approach on surgical morbidity and costs in women with endometrial carcinoma and hyperplasia. Gynecol Oncol 2017;145:55-60.

17. Lemert RM, Edwin M. Primary and Secondary Deviance. In: Cullen FT, Wilcox PK, eds. Encyclopedia of Criminological Theory. Thousand Oaks: SAGE Publications, Inc, 2010:551-3.

18. Lemert E. Human deviance, social problems, and social control. NJ: Prentice Hall: Englewood Cliffs, 1967.

19. Sandelowski M. Focus on qualitative methods. Qualitative analysis: what it is and how to begin. Research in Nursing \& Health 1995; $18: 371-5$

20. Thorne S, Kirkham SR, MacDonald-Emes J. Interpretive description: a noncategorical qualitative alternative for developing nursing knowledge. Res Nurs Health 1997;20:169-77.

21. Braun V, Clarke V. Using thematic analysis in psychology qualitative research in psychology. Qualitative Research in Psychology 2006;3:77-101.

22. Tracy SJ. Qualitative quality: Eight "big-tent" criteria for excellent qualitative research. Qualitative Inquiry 2010;16:837-51.

23. Forbes LJ, Warburton F, Richards MA, et al. Risk factors for delay in symptomatic presentation: a survey of cancer patients. $\mathrm{Br} J$ Cancer 2014:111:581-8.

24. Robb K, Stubbings S, Ramirez A, et al. Public awareness of cancer in Britain: a population-based survey of adults. Br J Cancer 2009;101 Suppl 2(Suppl 2):S18-S23.

25. Hooper L, Anderson AS, Birch J, et al. Public awareness and healthcare professional advice for obesity as a risk factor for cancer in the UK: a cross-sectional survey. J Public Health 2018;40:1-9.

26. Cram P, Fendrick AM, Inadomi J, et al. The impact of a celebrity promotional campaign on the use of colon cancer screening: the Katie Couric effect. Arch Intern Med 2003;163:1601-5.

27. Canada BC. See Red? See Your Doctor 2018.

28. Schmandt RE, Iglesias DA, Co NN, Nn C, et al. Understanding obesity and endometrial cancer risk: opportunities for prevention. Am J Obstet Gynecol 2011;205:518-25.

29. Dottino JA, Hasselblad V, Secord AA, et al. Levonorgestre intrauterine device as an endometrial cancer prevention strategy in obese women: A cost-effectiveness analysis. Obstet Gynecol 2016;128:747-53.

30. Jernigan AM, Maurer KA, Cooper K, et al. Referring survivors of endometrial cancer and complex atypical hyperplasia to bariatric specialists: a prospective cohort study. Am J Obstet Gynecol 2015;213:350.e1-350.e10

31. Clark LH, Ko EM, Kernodle A, et al. Endometrial cancer survivors perceptions of provider obesity counseling and attempted behavior change: Are we seizing the moment? Int J Gynecol Cancer 2016:26:318-24.

32. Fader AN, Arriba LN, Frasure HE, et al. Endometrial cancer and obesity: epidemiology, biomarkers, prevention and survivorship. Gynecol Oncol 2009;114:121-7.

33. Flint SW, Oliver EJ, Copeland RJ. Editorial: Obesity stigma in healthcare: Impacts on policy, practice, and patients. Front Psychol 2017;8:2149

34. Ramos Salas X, Alberga AS, Cameron E, et al. Addressing weight bias and discrimination: moving beyond raising awareness to creating change. Obes Rev 2017;18:1323-35.

35. Robinson J. Health at every size: Toward a new paradigm of weight and health. MedGenMed 2005;7:13.

36. Stitzenberg KB, Sigurdson ER, Egleston BL, et al. Centralization of cancer surgery: implications for patient access to optimal care. J Clin Oncol 2009;27:4671-8. 